\title{
Carotid Body Tumor: Experience from a Tertiary Care Hospital
}

Fahad Hanif Khan ${ }^{1 *}$, Kamal Muhammad Yousuf ${ }^{2}$ and Mishraz Shaikh ${ }^{3}$

${ }^{1}$ Department of General Surgery, Civil Hospital, Baba-e-Urdu Road, Karachi, Pakistan

${ }^{2}$ Department of Vascular Surgery, Liaquat National Hospital, Karachi, Sindh, Pakistan

${ }^{3}$ Department of General Surgery, Liaquat National Hospital, Karachi, Pakistan

"Corresponding author: Fahad Hanif Khan, Department of General Surgery, Civil Hospital, Baba-e-Urdu Road, Karachi, Pakistan, Tel: $92-21-3463$ 07 07; Fax: 341 40014; E-mail: dr.fhkhan@hotmail.com

Rec date: Apr 24, 2015; Acc date: May 27, 2015; Pub date: May 29, 2015

Copyright: $\odot 2015 \mathrm{Khan} \mathrm{FH}$, et al. This is an open-access article distributed under the terms of the Creative Commons Attribution License, which permits unrestricted use, distribution, and reproduction in any medium, provided the original author and source are credited.

Keywords: Carotid bodies; Chemodectoma; Tumor; surrounding nerves and invade the adjacent carotid artery making the Ultrasonography

\section{Introduction}

The carotid bodies are reddish brown, ellipsoid structures, embedded in the adventitia of the carotid artery at its bifurcation. Physiologically, they are known to be involved in the reflex control of heart rate, blood pressure and respiration [1]. A carotid body tumor (CBT), also called chemodectoma or non-chromaffin paraganglioma, is a rare tumor of common carotid artery [2]. The function of the carotid body is to protect the organ from hypoxia by releasing neurotransmitters. Though CBT is a rare tumor but it constitutes about $65 \%$ of the head and neck paragangliomas [3]. It occurs in middle aged people with higher predisposition in females [4] and those living at high altitudes or with diseases causing chronic hypoxemia like Fallot's tetralogy (TOF) or Chronic Obstructed Pulmonary Disease (COPD) [5].

Carotid body tumor usually present as a painless swelling at the anterior triangle of the neck beneath the sub-mandibular triangle [6]. A large tumor may compress surrounding nerves that may include hypoglossal nerve, glossopharyngeal nerve, recurrent laryngeal nerve and spinal accessory nerve giving rise to the symptoms of pain, hoarseness of voice, dysphagia or shoulder drop [7,8]. It can also compress and sometime displaces the pharynx.

Color Doppler ultrasonography is the most helpful investigation in the diagnosis of the disease. Computed Topographic Angiography (CTA) and Magnetic Resonance Imaging (MRI) are generally employed to delineate the anatomical relations of tumor and hence are helpful in making surgical decisions[6,9]. Digital Subtraction Angiography (DSA) is gold standard modality but nowadays it is reserved for those tumors which require pre-operative angioembolization [10].

The tumor can be grouped according to Shamblin et al. [11] classification for surgical management:

Class 1: Without encasement of the vessel wall, tumor size $<5 \mathrm{~cm}$, no widened carotid bifurcation.

Class 2: Tumor attached to the blood wall, but without encasement.

Class 3: Tumor attached to blood vessel with encasement of the blood wall, tumor size larger than $5 \mathrm{~cm}$ with widened carotid bifurcation.

According to the literature review these tumors are very unpredictable including a subset of benign tumors [12]. An early surgical excision at presentation is advisable since it can compress surgical excision difficult in later stages [10]. Carotid body tumors are not much explored in this region and a little clinical data is available from Pakistan. The main purpose of our study is to describe our experience in dealing with such rare and difficult tumors.

\section{Material and Methods}

All the cases of carotid body tumors who presented over a period of 10 years (2002-2012) at Liaquat National Hospital were studied. This teaching hospital is serving since last 50 years, with around 800 beds. It is one of the only two hospitals in Sindh province which provides vascular surgery services. Since the Afghan war, we have experienced a huge number of vascular injury patients coming from different parts of Pakistan and neighbouring countries. Being a teaching hospital it is our policy to take informed consent from the patients who have different or unique clinical presentations or rare diseases/diagnoses about the possible usage of the data (including clinical pictures) anonymously for research purposes at that time or in future. They can withdraw this consent any time if they want. The case notes of all identified patients were retrieved and reviewed. The study variables included patient demographics, presenting signs and symptoms, comorbidities, modality of diagnosis, management and outcome of the treatment given. The results were described in terms of descriptive statistics. The study has been approved by the institute's ethical review committee.

\section{Result}

A total of 18 patients of CBT presented during 2002-2012, including 11 females and 7 males, with median age at presentation of 40 years (range: 23-60 years). Out of 18 patients, 11 were referred from health care centers located at high altitude (1,500-1,700 meters) of the country where they were investigated with the suspicion of cold nodules. All (18) patients presented with painless swelling in the carotid triangle with 10 on the left side and 8 on the right side. The mean duration of symptoms was between $3.2 \pm 0.9$ years. 8 (44\%) patients were in Shamblin class I, $10(56 \%)$ in class II and none in class III (Figure 1). Color Doppler ultrasound (showing vascular neck mass with extent) and Computed Topographic Angiography (demonstrating densely vascular mass at the carotid bifurcation, splaying internal and external carotid artery) was done on all the patients except one who had MRI. One patient simultaneously had Tetralogy of Fallot and 1 had COPD. Tumor size varied from $2.2-6.2$ cms (mean: $4.0 \mathrm{cms} \pm 1.6$ ). 
Page 2 of 3

\section{Outcome}

Only 14 patients underwent surgical excision (Figure 2) with subadventitial dissection of the tumor (6 males, 8 females), 2 refused to have any intervention and 2 were deferred from surgical intervention due to co-morbidities (TOF and COPD). Out of 14 patients 2 had preoperative angio-embolization (with polyvinyl alcohol) to reduce tumor size ( $>6 \mathrm{cms}$ ). Mean hospital stay was 2.5 days. No complication occurred during or after the surgery and no blood transfusion was required. All specimens were sent for histo-pathological reporting which confirmed the presence of carotid body tumor (pseudo-alveolar arrangement of type I and type II cells). Patients were followed after 1, 4,10 weeks and 2 years after the procedure, as per departmental policy. Twelve patients had complete follow up according to the schedule; however 2 patients lost follow up after 10 weeks. Two patients, who refused to undergo surgical intervention, were referred back to primary physician for follow-up.

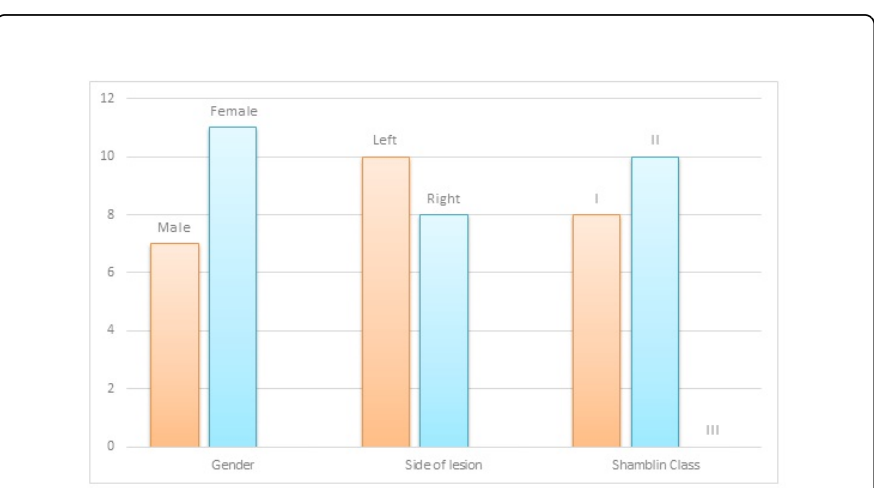

Figure 1: Characteristics of patients $(\mathrm{n}=18)$.

\section{Discussion}

Carotid body tumors are rare neoplasms, although they represent most common head and neck paraganglionomas, which makes their diagnosis and management difficult [2]. CBT is generally benign but its benign forms have no true capsule and grow progressively [6], adhering to and encasing the vessels and nerves, compressing and dislocating the pharynx and even eroding the base of the skull; therefore they should never be left untreated even if benign [12]. In our study the affected age group was between 23 to 60 years CBT is often seen in patients between the age 50 to 70 years with higher incidence in female than in male [13]. The main signs and symptoms of CBT include a slow growing mass at the level of carotid bifurcation with or without a peripheral cervical neuropathy related to large tumors [3]. Duration of symptoms in our study was 2-4 years from the beginning of the swelling but the tumor may be clinically silent for a longer duration even when malignant. Due to its close approximation to carotid vessels and lower cranial nerves (10th - 12th), patients may present with symptoms related to the nerve involvement as voices changes, difficulty in swallowing and other related cranial nerve deficits and with symptoms of catecholamine production as sleep apnea, blushing or palpitations [14,15]. Color Doppler ultrasonography and DSA plays a very important role in confirmation of the clinical diagnosis of CBTs [16]. Digital Subtraction Angiography is regarded as the gold standard for the final diagnosis [10], however due to unavailability and high cost of this facility it was not used as diagnostic modality. Carotid body tumors are treated with either surgery or radiotherapy. Surgery is usually the treatment of choice for patients with no comorbid [6,17]. Surgical excision with subadventitial dissection is deemed to be enough for Shamblin I and II tumors, however for Shamblin III a more planned approach is needed as it requires resection and repair of vascular segment and clamping/ shunts to control massive intra-operative blood loss [3].

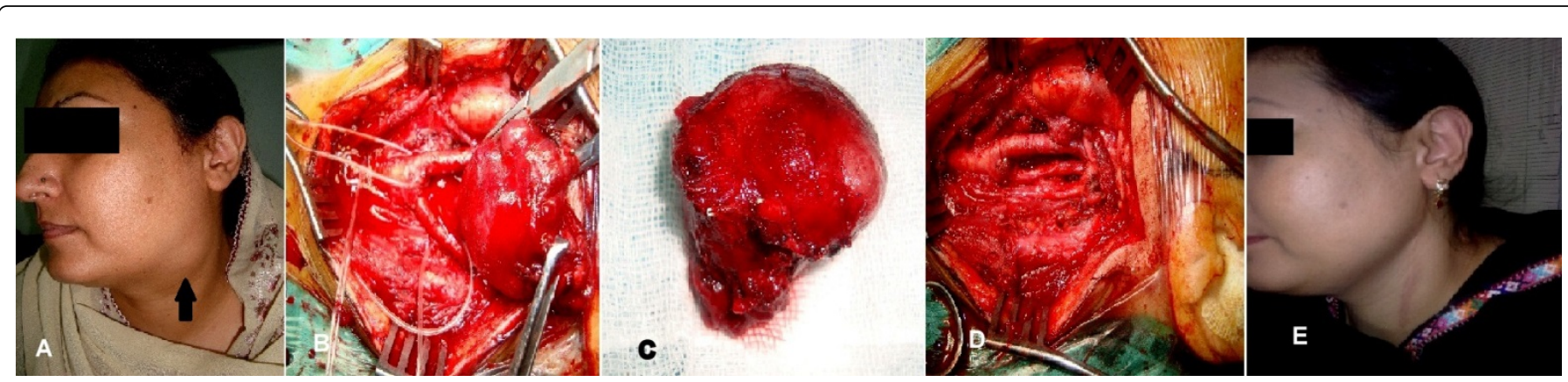

Figure 2: Lady diagnosed as having CBT (A) underwent surgical excision of the tumor at carotid bifurcation (B, C, and D). The patient recovered well from the procedure (E).

Two of our patients underwent pre-operative angio-embolization since, studies have shown that this technique decreases intra-operative blood loss and simplifies the anatomy by shrinking the tumor size, though it does not help in reducing the rate of cranial nerve injuries [17-21]. Even with sophisticated surgical excision, there is still high percentage of nerve injuries, pseudo-aneurym formation $[22,23]$ and tumor recurrences on long term follow-up [24], though we observed no post-operative complications and recurrences in our study group. Radiotherapy is usually reserved for elderly patients with co-morbids because of the potential serious operative injuries and risks of stroke- induced by the surgical procedure, for recurrences and for metastatic disease [25-27]. Radiotherapy alone can effectively prolong the survival period of patients who cannot undergo surgery [28].

\section{Conclusion}

Surgical excision by a vascular surgeon, with or without preoperative angio-embolization, remains the mainstay treatment for $\mathrm{CBT}$ as to avoid the possibility of metastasis and to halt local invasion to the point of inoperability. 


\section{Limitations}

This is a retrospective single center experience which is a main limitation of this study. We have observed a small number of patients over a period of 10 years as the disease addressed is a rare entity. A more extensive and collaborative research is required to support the results.

\section{References}

1. Kairemo KJ, Hopsu EV (1990) Radioimmunodetection of chemodectoma by In-111 labeled anti-CEA antibody. Case report and review of the literature. Clin Nucl Med 15: 900-903.

2. Knight TT Jr, Gonzalez JA, Rary JM, Rush DS (2006) Current concepts for the surgical management of carotid body tumor. Am J Surg 191: 104-110.

3. Davidovic LB, Djukic VB, Vasic DM, Sindjelic RP, Duvnjak SN (2005) Diagnosis and treatment of carotid body paraganglioma: 21 years of experience at a clinical center of Serbia. World J Surg Oncol 3: 10.

4. Luo T, Zhang C, Ning YC, Gu YQ, Li JX, et al. (2013) Surgical treatment of carotid body tumor: case report and literature review. J Geriatr Cardiol 10: 116-118.

5. Yildiz BS, Sasmazel A, Baysal A, Gozu HI, Erturk E, et al. (2014) Assessment of carotid body tumor and its association with tetralogy of fallot: effect of the chronic hypoxia. Heart Views 15: 86-88.

6. Patlola R, Ingraldi A, Walker C, Allie D, Khan IA (2010) Carotid body tumor. Int J Cardiol 143: e7-7e10.

7. Sanli A, Eken M, Aydin S, Paksoy M, Yildirim M (2003) A case of carotid body tumor. Kulak Burun Bogaz Ihtis Derg 11: 148-151.

8. Calbo L, Sciglitano P, Calbo E, Niceta M, Borzì R, et al. (2009) [Carotid body tumor. An often misdiagnosed disease]. G Chir 30: 144-147.

9. Sharma G, Sharma AK, Jindel D, Sharma D (2010) Carotid body tumor. Indian J Surg 72: 365-366.

10. Ma D, Liu M, Yang H, Ma X, Zhang C (2010) Diagnosis and surgical treatment of carotid body tumor: A report of 18 cases. J Cardiovasc Dis Res 1: 122-124.

11. Makeieff M, Raingeard I, Alric P, Bonafe A, Guerrier B, et al. (2008) Surgical management of carotid body tumors. Ann Surg Oncol 15: 2180-2186.

12. Ling FJ, Weinrach DM, Eskandari MK (2004) Carotid body tumor--a case report. Vasc Endovascular Surg 38: 185-188.

13. Sobol SM, Dailey JC (1990) Familial multiple cervical paragangliomas: report of a kindred and review of the literature. Otolaryngol Head Neck Surg 102: 382-390.

14. Defraigne JO, Sakalihassan N, Antoine P, Thiry A, Limet R (1997) Carotid chemodectomas. Experience with nine cases with reference to preoperative embolization and malignancy. Acta Chir Belg 97: 220-228.
15. Metersky ML, Castriotta RJ, Elnaggar A (1995) Obstructive sleep apnea due to a carotid body paraganglioma. Sleep 18: 53-54.

16. Mayer R, Fruhwirth J, Beham A, Groell R, Poschauko J, et al. (2000) Radiotherapy as adjunct to surgery for malignant carotid body paragangliomas presenting with lymph node metastases. Strahlenther Onkol 176: 356-360.

17. San Norberto EM, Taylor JH, Carrera S, Vaquero C (2012) Intraoperative embolization with poloxamer 407 during surgical resection of a carotid body tumor. J Vasc Surg 56: 1782-1785.

18. Power AH, Bower TC, Kasperbauer J, Link MJ, Oderich G, et al. (2012) Impact of preoperative embolization on outcomes of carotid body tumor resections. J Vasc Surg 56: 979-989.

19. Yang T H, Ou C H, Yang M S, Lee Y C, Yeh L R (2011) Preoperative embolization of carotid body tumor by direct percutaneous intratumoral injection of N-butyl cyanoacrylate glue assisted with balloon protection technique. J Chin Med Assoc 74: 91-4.

20. Li J, Wang S, Zee C, Yang J, Chen W, et al. (2010) Preoperative angiography and transarterial embolization in the management of carotid body tumor: a single-center, 10-year experience. Neurosurgery 67: 941-948.

21. Tang F, Han D, Qu S, Liang J, Liu B, et al. (2014) Diagnosis and management of jugulare glomus tumor and carotid body tumor. Lin Chung Er Bi Yan Hou Tou Jing Wai Ke Za Zhi 28: 612-617.

22. Hotze TE, Smith TA, Clagett GP (2011) Carotid artery pseudopseudoaneurysm after excision of carotid body tumor. J Vasc Surg 54: 864 .

23. Ramesh A, Muthukumarassamy R, Karthikeyan VS, Rajaraman G, Mishra S (2013) Pseudoaneurysm of internal carotid artery after carotid body tumor excision. Indian J Radiol Imaging 23: 208-211.

24. Pandey M, Chandramohan K, Sebastian P, Ramachandran K (2002) An unusual bilateral cervical paraganglioma: a case report. Int $\mathrm{J}$ Oral Maxillofac Surg 31: 334-336.

25. Zabel A, Milker-Zabel S, Huber P, Schulz-Ertner D, Schlegel W, et al. (2004) Fractionated stereotactic conformal radiotherapy in the management of large chemodectomas of the skull base. Int J Radiat Oncol Biol Phys. 58: 1445 - 1450.

26. Elshaikh MA, Mahmoud-Ahmed AS, Kinney SE, Wood BG, Lee JH, et al. (2002) Recurrent head-and-neck chemodectomas: a comparison of surgical and radiotherapeutic results. Int J Radiat Oncol Biol Phys 52: 953-956.

27. Hinerman RW, Mendenhall WM, Amdur RJ, Stringer SP, Antonelli PJ, et al. (2001) Definitive radiotherapy in the management of chemodectomas arising in the temporal bone, carotid body, and glomus vagale. Head Neck 23: 363-371.

28. Valdagni R, Amichetti M (1990) Radiation therapy of carotid body tumors. Am J Clin Oncol 13: 45-48. 